\title{
Antioxidant bioactive compounds and spoilage microorganisms of wax apple (Syzygium samarangense) during room temperature storage
}

\begin{abstract}
Postharvest deterioration of wax apple leads to unacceptable appearances, physical and quality losses that raise serious concerns commercially. Bioactive compounds of wax apple and spoilage microorganisms were studied at room temperature storage $\left(23 \pm 1{ }^{\circ} \mathrm{C}\right)$. Antioxidant activity and total phenolic content increased up to a maximum of $1.56 \mathrm{mg}$ AAE/100 g and $88.37 \mathrm{mg} \mathrm{GAE} / 100 \mathrm{~g}$, while prolonged storage resulted in $70.0 \%$ and $33.6 \%$ loss, respectively. Further, $80 \%$ loss in vitamin $\mathrm{C}$ content was observed from an initial value of $21.63 \mathrm{mg}$ AAE/100 g during storage. Bacterial isolates of Enterobacter sakazakii, Klebsiella pneumoniae, Klebsiella planticola, Pantoea agglomerans, Chromobacterium violaceum, and Streptomyces roseochromogenus with microbial load of $1.19 * 10^{8} \mathrm{CFU} / \mathrm{g}$ fresh weight, and fungal isolates of Penicillium purpurogenum, Mucor hiemalis, Aspergillus niger, Aspergillus fumigatus, and Candida tropicalis with a total load of $5.64 * 10^{7} \mathrm{CFU} / \mathrm{g}$ fresh weight were identified as spoilage organisms. Bacterial isolates of Klebsiella pneumoniae was the most prevalent at $47.78 \%$, occurring 21 times, while Penicillium purpurogenum was the most prevalent fungi, occurring 5 times at $38.46 \%$. Results have significant implications on measures to preserve quality of wax apples during storage by adoption of advanced postharvest handling and processing approaches.
\end{abstract}

Keyword: Total phenols; Bacteria; Fungi; Postharvest; Antioxidant activity; Vitamin C 